\title{
Daylight Adaptive Shading Using Parametric Camshaft Mechanism for SOHO in Jakarta
}

\author{
Firza Utama Sjarifudin ${ }^{1, a}$ and Laurensia Justina ${ }^{2}$ \\ ${ }^{1}$ Bina Nusantara University, Architecture Department, J1. KH Syahdan no:9 Kemanggisan, Jakarta 11530, Indonesia \\ ${ }^{2}$ Bina Nusantara University, Architecture Department, Jl. KH Syahdan no:9 Kemanggisan, Jakarta 11530, Indonesia
}

\begin{abstract}
This research analyzes SOHO (Small Office Home Office) which can adjust to the need of visual comfort for the users through natural daylighting and also can be adapted to standard requirements of 14 creative industry workspace in Jakartas. The method of the research is by simulating the SOHO unit with variation of shading opening angles in order to adapt to each unit. Analysis done to every shading opening angle to get the appropriate daylight intensity level which support the work activities in every unit for the whole day. In order for the shading to be able to adapt to the changing daylight condition, previously developed parametric camshaft mechanism was used. The study found that the visual comfort for SOHO with creative industries workers in Jakarta can be achieve by varying the shading opening angles between 15-75.
\end{abstract}

\section{Introduction}

Most of Small office/Home office (SOHO) building are mezzanine type, with the office space on the lower floor and a private room on the upper floor. Certain proffesions that are primarily engaged in the creative industries lives and works in SOHO building, such as architects, graphic designers, writers, photographers, musicians, etc, because generally their offices do not require too much space ${ }^{[1]}$.

Effective use of daylighting plays important role for visual comfort in SOHO. Different daylight intensity needs for each creative industry varies depending on their type of working activity.

The use of adaptive shading could provide sufficient daylighting intensity for different SOHO units. The nature of the adaptive shading is that it can adapt to changing daylight conditions. Changes in the movement of sun per day and per year resulting in daylight intensity value received at any part of the grid surface of the building to be always changing. By applying adaptive shading solutions that specifically follows the changes in every part of the grid will be able to comply every visual comfort requirements.

In order for every part of adaptive shading to be able to move, large numbers of motors, sensors, and drivers are used. In order to operate that apparatus requires electrical energy. Even with the use of photovoltaic, high costs will be required to produce such a device. Besides, mechatronics equipment, especially motors, has limited period of use, therefore the cost for maintenance and replacement of equipment will contribute to the high expenditure, and this will result in the overall energy

\footnotetext{
${ }^{a}$ Corresponding author: fsjarifudin@binus.edu
}

inefficiency and the level of sustainability to be achieved can be very low.

Therefore, this study also proposed a system that can reduce the kinetic mechanism problems of the above issues in order to lower production costs, save energy consumption of the appliance and maintenance by applying parametric camshaft methods. By using this method will reduce the amount of motor usage at each grid and make it more centralized, this method could also reduce the number of motor drivers, and replace the use of sensors with environmental analysis data values.

\section{Related research}

Recent studies have shown that appropriate shading design and control, linked with simultaneous control of electric lighting and HVAC components, could significantly reduce peak cooling load and energy consumption for lighting and cooling, while maintaining good thermal and lighting indoor conditions ${ }^{[2]}$. There has been a growing interest to include intelligence in buildings to be energy efficient. Smart architectural design decision or intelligent technological devices can do it. Their defined active features are elements of buildings, which can self-adjust to the changes initiated by external environment ${ }^{[3]}$. By actuating the facades and making them dynamic, they can now better adapt to the conditions and provide for improved comfort of the occupants. Facades can now sense the environment and 
make their own modifications in order to achieve prescribed goals. The building can be constantly working towards a better environment for the user as opposed to simply protecting them from it ${ }^{[4]}$. By studying the many existing kinetic building skin systems and through the use of computer simulations and empirical testing, a sampling of the methods of kinetic movement can be analysed for their environmental benefits, compared to each other, and recommendations proposed ${ }^{[5]}$. Parametric design method can effectively make the building modelling and its configuration connected to the real world climatic parameters, and facilitates the study of building sustainability related to energy efficiency and it also offers an important way to explore the kinetic building components ${ }^{[6,7]}$.

The above researches have described that the mainstream drivers for adaptive and kinetic building components are sustainability and energy efficiency, however the adoptation of high-tech envelopes has been slow, sceptical architects foresee them being unplugged and later stripped off their building due to poor performance, broken actuators or deficient maintenance, plainly the road to the interactive envelope is a rough one [8].

These studies and literatures of kinetic and adaptive building issues present our research with the practical and sustainable insight into how to explore and manage the building envelope behaviours to the environment. The originality of this paper is to develop new system for adaptive shading to be more suitable to the lighting requirements for 14 creative industries in a SOHO units in Jakarta.

\section{Methods}

The study was conducted as follows, firstly this study focused on building mass study and orientation arrangement of the building mass by analyzing shadow range on March 21, June 21, September 23, and December 22, between 8:00 AM to 17:00 PM.

Next, a study on SOHO units was conducted by analyzing standard layout space requirements for creative industries in accordance with existing workspace standards in Jakarta.

Moreover, study on adaptive shading was conducted by analyzing daylight level to find the appropriate shading opening angle and obtain effective visual comfort requirements for 14 creative industries according to the IES standard.

Furthermore, the analysis result of adaptive shading study was used to generate kinetic mechanism using parametric camshaft method ${ }^{[9]}$.

The general setup in this study are as follows:

Site location : Jakarta, Puri Indah Superblock

Latitude $\quad:-6.1000^{\circ}$,

Longtitude $\quad: 106.7000^{\circ}$

Date : March 21, June 21, September 23, and December 22.
Time

: Pk 09:00, Pk 12:00, dan Pk 15:00

Building Orientation : South, Southwest, Southeast, and North

Analyzed Floors

Room Dimension

Sky condition

Software

\author{
: 1st, 10th, 20th floor \\ : $6 \mathrm{~m} \times 9 \mathrm{~m}$ \\ : Sunny with Sun \\ : Ecotect Analysis dan Radiance
}

\section{Result}

The result from the building mass and orientation study have found that the best orientations are South, North, Southwest, and Southeast. Figure 1 shows the screenshot of shadow range analysis.

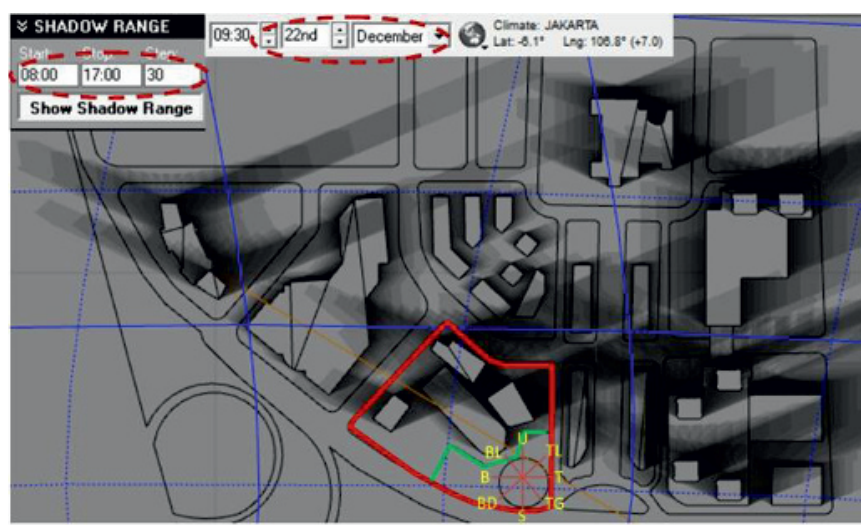

Figure 1. Shadow range study of surrounding buildings.

The result from the study of SOHO unit in Jakarta was found that workspaces for creative industry offices can be groupped by 3 types of room dimension $\left(60-80 \mathrm{~m}^{2}, 80\right.$ $\left.90 \mathrm{~m}^{2}, 90-110 \mathrm{~m}^{2}\right)$. Table 1 shows the group of industries and its space requirements.

The result from the visual comfort requirements study based on IES standard can be found that 4 types of lighting level can be applied. Table 2 shows the lighting level requirements for each industry workspace.

Following study was to determine the model of room and shading device. The room model was set to the average SOHO dimension in Jakarta (width: $6 \mathrm{~m}$, length:9m, height: $6 \mathrm{~m})$. The dimension of shading device was set to fit the unit facade $(6 \mathrm{~m} \times 6 \mathrm{~m})$, and the fin was: $6 \mathrm{~m} \times 50 \mathrm{~cm}$. The daylight level was measured at the height of the workin plane, in this study was set at the height of $90 \mathrm{~cm}$, and the depth of $450 \mathrm{~cm}$. Figure 3 shows the room and shading device dimension.

The study of adaptive shading was initially conducted by comparing facade without any shading, and with vertical / horizontal types of shading, the result of the simulation shows that the use of shading on SOHO unit can lower the intensity of light coming into the room and the use of horizontal shading can reduce the intensity of light coming into the room higher than vertical shading. Figure 3 shows the comparison of daylight simulation using vertical and horizontal shading using Radiance. 
Table 1. Space requirements for 14 creative industry units

\begin{tabular}{|c|c|c|}
\hline $60-80 \mathrm{~m}^{2}$ & $80-90 \mathrm{~m}^{2}$ & $90-110 \mathrm{~m}^{2}$ \\
\hline Advertising & Architecture & Performing Art \\
\hline Computer Services & Design & Video, Film, Photography \\
\hline Interactive Games & Handycraft Store & Television \\
\hline Fashion & Craft & Research \& Development \\
\hline Music & Publisher & - \\
\hline Radio & - & - \\
\hline
\end{tabular}

Table 2. Lighting level requirements for 14 creative industry workspace.

\begin{tabular}{|c|c|c|}
\hline & $\begin{array}{c}\text { Types of creative } \\
\text { industries }\end{array}$ & IES Standard \\
\hline \multirow{3}{*}{ I } & Architecture & \multirow{3}{*}{750 lux } \\
\hline & Design & \\
\hline & Fashion & \\
\hline \multirow{2}{*}{ II } & Handycraft Store & \multirow{2}{*}{600 lux } \\
\hline & Craft & \\
\hline \multirow{6}{*}{ III } & Advertising & \multirow{6}{*}{500 lux } \\
\hline & Video, Film, Photography & \\
\hline & Interactive Games & \\
\hline & Publisher & \\
\hline & Research \& Development & \\
\hline & Computer Services & \\
\hline \multirow{4}{*}{ IV } & Performing Art & \multirow{4}{*}{350 lux } \\
\hline & Music & \\
\hline & Radio & \\
\hline & Television & \\
\hline
\end{tabular}

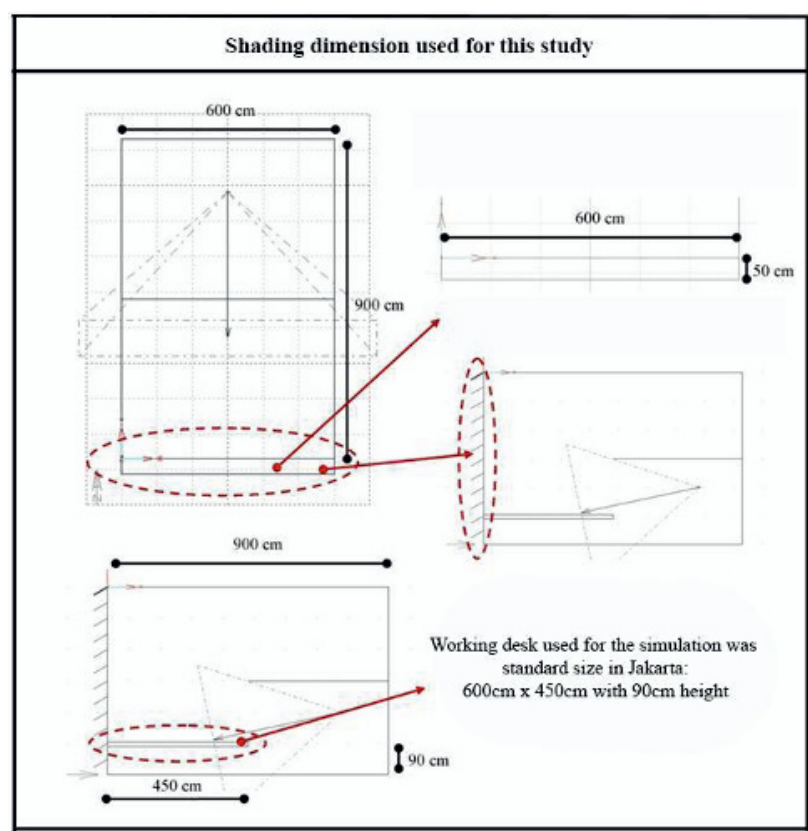

Figure 2. Shading and room dimension used for shading angle study

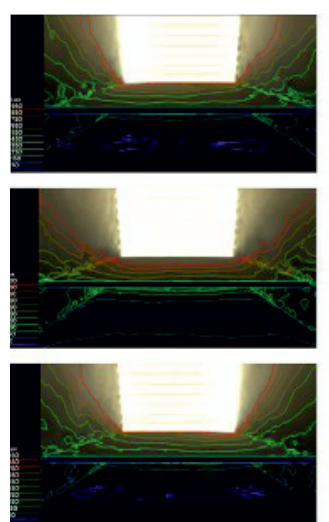

Pk 09.00

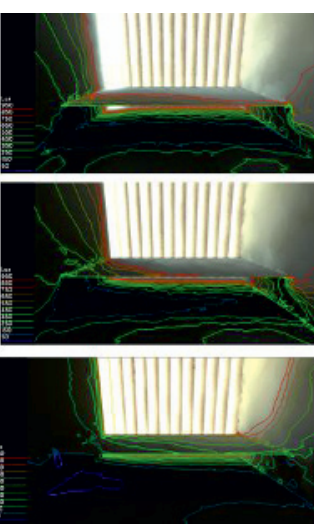

Figure 3. Vertical and Horizontal shading comparison in Radiance.

Following study was conducted to find the suitable shading angle for South, Southwest, Southeast, and North orinentation of the units. Table 3,4 , and 5 shows required daylighting levels on each time and building orientation, from the effect of different shading angles.

From the daylight level analysis at the time of building units facing South, Southwest, Southeast, and North before using shading is 950 lux but when using shading can reduce the level of daylighting. Angles used in this study to meet the standards requirements from 350 to 750 lux.

On 12:00 AM Building facing South and North should use an opening angle of $30^{\circ}$. When using angles smaller than $30^{\circ}$ the daylight level in the room could exceed the standard requirement.

On 3:00 PM Building facing Southwest should use an opening angle of $45^{\circ}$. When using angles smaller than $45^{0}$ the daylight level in the room could exceed the standard requirement.

On 9:00 AM Building facing Southwest should use an opening angle of $45^{\circ}$. When using angles smaller than $45^{0}$ the daylight level in the room could exceed the standard requirement.

Based on the analysis on different floor heights (10, 20, 30, and 40) can be concluded that in fact building height affects the amount of daylighting on each unit. The higher the level of SOHO unit, the higher the intensity of light that can enter the unit.

Furthermore, detailed analysis on the shading device formation changes of its fins was conducted and 8 different shading (fin) formation was found. Table 6 shows These formation would be used accordingly to adapt to the changing daylight condition throughout the day. Based on these formation, further study on the mechanism was conducted in order to develop simplified model of the adaptive shading using paramteric camshaft method. 
Table 3. Workspace daylighting levels on 1st floor

\begin{tabular}{|c|c|c|c|c|c|c|c|}
\hline \multicolumn{8}{|c|}{ Omice davlighting levels on 1st floor } \\
\hline \multirow{3}{*}{$\begin{array}{l}\text { DL } \\
\text { Staudur }\end{array}$} & \multirow{3}{*}{$\begin{array}{l}\text { Builling } \\
\text { Orientatiou }\end{array}$} & \multicolumn{6}{|c|}{ Daylighting levels on oflice desk height } \\
\hline & & \multicolumn{2}{|c|}{09.40} & \multicolumn{2}{|c|}{12.00} & \multicolumn{2}{|c|}{15.00} \\
\hline & & Lax & $\begin{array}{l}\text { Shading } \\
\text { Angle }\end{array}$ & Lux & $\begin{array}{l}\text { Shading } \\
\text { Augle }\end{array}$ & Lax & $\begin{array}{c}\text { Shading } \\
\text { Angle }\end{array}$ \\
\hline \multirow{4}{*}{750 Lux } & South & $450-950$ & $15^{a}$ & $450-950$ & $30^{\prime \prime}$ & $450-950$ & $15^{\circ}$ \\
\hline & Southwest. & $450-950$ & $15^{\circ}$ & $450-950$ & $30^{2}$ & $550-950$ & $45^{\circ}$ \\
\hline & Southeast & $550-950$ & $45^{\circ}$ & $450-950$ & $30^{\circ}$ & $450-950$ & $15^{\circ}$ \\
\hline & North & $450-950$ & $15^{\circ}$ & $450-950$ & $30^{2}$ & $450-950$ & $15^{\circ}$ \\
\hline \multirow{4}{*}{$600 \mathrm{Lux}$} & South & $350-850$ & $30^{\circ}$ & $250-950$ & $45^{\circ}$ & $350-850$ & $30^{\circ}$ \\
\hline & Southwest & $350-950$ & $15^{\circ}$ & $350-950$ & $45^{\pi}$ & $250-950$ & $60^{\circ}$ \\
\hline & Southeast & $250-950$ & $60^{a}$ & $350-950$ & $45^{\prime \prime}$ & $350-950$ & $15^{\circ}$ \\
\hline & North & $350-850$ & $30^{\circ}$ & $250-950$ & $45^{\circ}$ & $350-850$ & $30^{\circ}$ \\
\hline \multirow{4}{*}{500 Lux } & South & $250-750$ & $45^{\circ}$ & $350-750$ & $60^{\circ}$ & $250-650$ & $45^{\circ}$ \\
\hline & Southwest. & $250-750$ & $30^{\circ}$ & $250-750$ & $60^{2}$ & $250-750$ & $60^{\circ} \& 75^{\circ}$ \\
\hline & Southeast & $350-650$ & $60^{\circ} \& 75^{\circ}$ & $350-750$ & $60^{2}$ & $350-650$ & $30^{\circ}$ \\
\hline & North & $250-750$ & $45^{\circ}$ & $350-750$ & $60^{\circ}$ & $250-650$ & $45^{\circ}$ \\
\hline \multirow{4}{*}{350 Lux } & South & $150-450$ & $60^{\circ}$ & $150-550$ & $60^{\circ} \& 75^{\circ}$ & $150-550$ & $60^{\circ}$ \\
\hline & Southwest & $150-650$ & $45^{\circ}$ & $150-650$ & $60^{\circ} \& 75^{\circ}$ & $150-650$ & $60^{\circ} \& 75^{\circ}$ \\
\hline & Southeast & $150-650$ & $60^{\circ} \& 75^{2}$ & $150-650$ & $60^{\circ} \& 75^{\circ}$ & $150-650$ & $45^{\circ}$ \\
\hline & North & $150-450$ & $60^{\circ}$ & $150-550$ & $60^{\circ} \& 75^{\circ}$ & $150-550$ & $60^{\circ}$ \\
\hline
\end{tabular}

Table 4. Workspace daylighting levels on 10th floor

\begin{tabular}{|c|c|c|c|c|c|c|c|}
\hline \multicolumn{8}{|c|}{ Office daytighting levels on 10st floor } \\
\hline \multirow{3}{*}{$\begin{array}{c}\text { DL } \\
\text { Standar }\end{array}$} & \multirow{3}{*}{$\begin{array}{l}\text { Buildihg } \\
\text { Ortentation }\end{array}$} & \multicolumn{6}{|c|}{ Daylighting levels on office desk height } \\
\hline & & \multicolumn{2}{|c|}{09.00} & \multicolumn{2}{|c|}{12.90} & \multicolumn{2}{|c|}{ 15.90 } \\
\hline & & Lux & $\begin{array}{l}\text { Shating } \\
\text { Angle }\end{array}$ & Lux & $\begin{array}{c}\text { Shauling } \\
\text { Angle }\end{array}$ & Lux & $\begin{array}{l}\text { Shading } \\
\text { Angle }\end{array}$ \\
\hline \multirow{4}{*}{$750 \mathrm{Lux}$} & South & $450-950$ & $15^{\circ}$ & $450-950$ & $30^{\circ}$ & $450-950$ & $15^{\circ}$ \\
\hline & Southwest & $450-950$ & $15^{\circ}$ & $550-950$ & $30^{\circ}$ & $550-950$ & $45^{\circ}$ \\
\hline & Southeast & $550-950$ & $45^{\circ}$ & $450-950$ & $30^{\circ}$ & $450-950$ & $15^{\mathrm{m}}$ \\
\hline & North & $450-950$ & $15^{\circ}$ & $450-950$ & $30^{\circ}$ & $450-950$ & $15^{\circ}$ \\
\hline \multirow{4}{*}{$600 \mathrm{Lux}$} & South & $350-950$ & $30^{\circ}$ & $350-950$ & $45^{\circ}$ & $350-850$ & $30^{\circ}$ \\
\hline & \begin{tabular}{|l|} 
Southwest \\
\end{tabular} & $350-950$ & $15^{\circ}$ & $350-950$ & $45^{\circ}$ & $250-950$ & $60^{\circ}$ \\
\hline & Southeast & $250-950$ & $60^{\circ}$ & $350-950$ & $45^{\circ}$ & $350-950$ & $15^{\circ}$ \\
\hline & North & $350-950$ & $30^{\circ}$ & $350-950$ & $45^{\circ}$ & $350-850$ & $30^{\circ}$ \\
\hline \multirow{4}{*}{500 Lux } & South & $250 \cdot 750$ & $45^{\circ}$ & $250 \cdot 750$ & $60^{\circ}$ & $250-650$ & $45^{\circ}$ \\
\hline & Southwest & $250-750$ & $30^{\circ}$ & $250-750$ & $60^{\circ}$ & $250-750$ & $60^{\circ} \& 75^{\circ}$ \\
\hline & Southeast & $250-750$ & $60^{\circ} \& 75^{\circ}$ & $250-750$ & $60^{\circ}$ & $250-750$ & $30^{\circ}$ \\
\hline & North & $250-750$ & $45^{\circ}$ & $250-750$ & $60^{\circ}$ & $250-650$ & $45^{\circ}$ \\
\hline \multirow{4}{*}{$350 \mathrm{Lux}$} & South & $150-450$ & $60^{\circ}$ & $150-550$ & $60^{\circ} \& 75^{\circ}$ & $150-550$ & $60^{\circ}$ \\
\hline & Southwest & $150-650$ & $45^{\circ}$ & $150-650$ & $60^{\circ} \& 75^{\circ}$ & $150-650$ & $60^{\circ} \& 75^{\circ \mathrm{cm}}$ \\
\hline & Southeast & $150-650$ & $60^{\circ} \& 75^{\circ}$ & $150-650$ & $60^{\circ} \& 75^{\circ}$ & $150-650$ & $45^{\circ}$ \\
\hline & North & $150-450$ & $60^{\circ}$ & $150-550$ & $60^{\circ} \& 75^{\circ}$ & $150-550$ & $60^{\circ}$ \\
\hline
\end{tabular}

Table 5. Workspace daylighting levels on 20th floor

\begin{tabular}{|c|c|c|c|c|c|c|c|}
\hline \multicolumn{8}{|c|}{ Office daylighting levels on 20th floor } \\
\hline \multirow{3}{*}{$\begin{array}{c}\text { DL } \\
\text { Standar }\end{array}$} & \multirow{3}{*}{$\begin{array}{c}\text { Building } \\
\text { Orientation }\end{array}$} & \multicolumn{6}{|c|}{ Daylighting levels on oflice desk height } \\
\hline & & \multicolumn{2}{|c|}{09.00} & \multicolumn{2}{|c|}{12.00} & \multicolumn{2}{|c|}{15.00} \\
\hline & & Lux & $\begin{array}{c}\text { Shading } \\
\text { Angle }\end{array}$ & Lux & $\begin{array}{c}\text { Shading } \\
\text { Angle }\end{array}$ & Lux & $\begin{array}{c}\text { Shading } \\
\text { Angle }\end{array}$ \\
\hline \multirow{4}{*}{$750 \operatorname{Lux}$} & South & $450-950$ & $15^{\circ}$ & $550-950$ & $30^{\circ}$ & $450-950$ & $15^{\circ}$ \\
\hline & South West & $450-950$ & $15^{\circ}$ & $550-950$ & $30^{\circ}$ & $550-950$ & $45^{\circ}$ \\
\hline & South East & $550-950$ & $45^{\circ}$ & $550-950$ & $30^{\circ}$ & $450-950$ & $15^{\circ 1}$ \\
\hline & North & $450-950$ & $15^{\circ}$ & $550-950$ & $30^{\circ}$ & $450-950$ & $15^{\circ}$ \\
\hline \multirow{4}{*}{$600 \mathrm{Lux}$} & South & $350-950$ & $30^{\circ}$ & $350-850$ & $45^{\circ} \& 60^{\circ}$ & $350-950$ & $30^{\circ}$ \\
\hline & South West & $350-950$ & $15^{\circ}$ & $350-950$ & $45^{\circ}$ & $350-950$ & $60^{\circ}$ \\
\hline & South East & $350-950$ & $60^{\circ}$ & $350-950$ & $45^{\circ}$ & $350-950$ & $15^{\circ}$ \\
\hline & North & $350-950$ & $30^{\circ}$ & $350-850$ & $45^{\circ} \& 60^{\circ}$ & $350-950$ & $30^{\circ}$ \\
\hline \multirow{4}{*}{$500 \operatorname{Lux}$} & South & 250.750 & $45^{\circ}$ & $250-850$ & $60^{\circ}$ & $250-750$ & $45^{\circ}$ \\
\hline & South West & $250-750$ & $30^{\circ}$ & $250-850$ & $60^{\circ}$ & $250-850$ & $60^{\circ} \& 75^{\circ}$ \\
\hline & South East & $250-850$ & $60^{\circ} \& 75^{\circ}$ & $250-850$ & $60^{\circ}$ & $250-750$ & $30^{\circ}$ \\
\hline & North & $250-750$ & $45^{\circ}$ & $250-850$ & $60^{\circ}$ & $250-750$ & $45^{\circ}$ \\
\hline \multirow{4}{*}{$350 \mathrm{Lax}$} & South & $150-550$ & $60^{\circ}$ & $150-550$ & $60^{\circ} \& 75^{\circ}$ & $150-550$ & $60^{\circ}$ \\
\hline & South West & $150-550$ & $45^{\circ} \& 60^{\circ}$ & $150-650$ & $60^{\circ} \& 75^{\circ}$ & $150-650$ & $60^{\circ} \& 75^{\circ}$ \\
\hline & South East & $150-650$ & $60^{\circ} \& 75^{\circ}$ & $150-650$ & $60^{\circ} \& 75^{\circ}$ & $150-550$ & $45^{\circ} \& 60^{\circ}$ \\
\hline & North & $150-550$ & $60^{\circ}$ & $150-550$ & $60^{\circ} \& 75^{\circ}$ & $150-550$ & $60^{\circ}$ \\
\hline
\end{tabular}

Table 6. Shading angle formation types

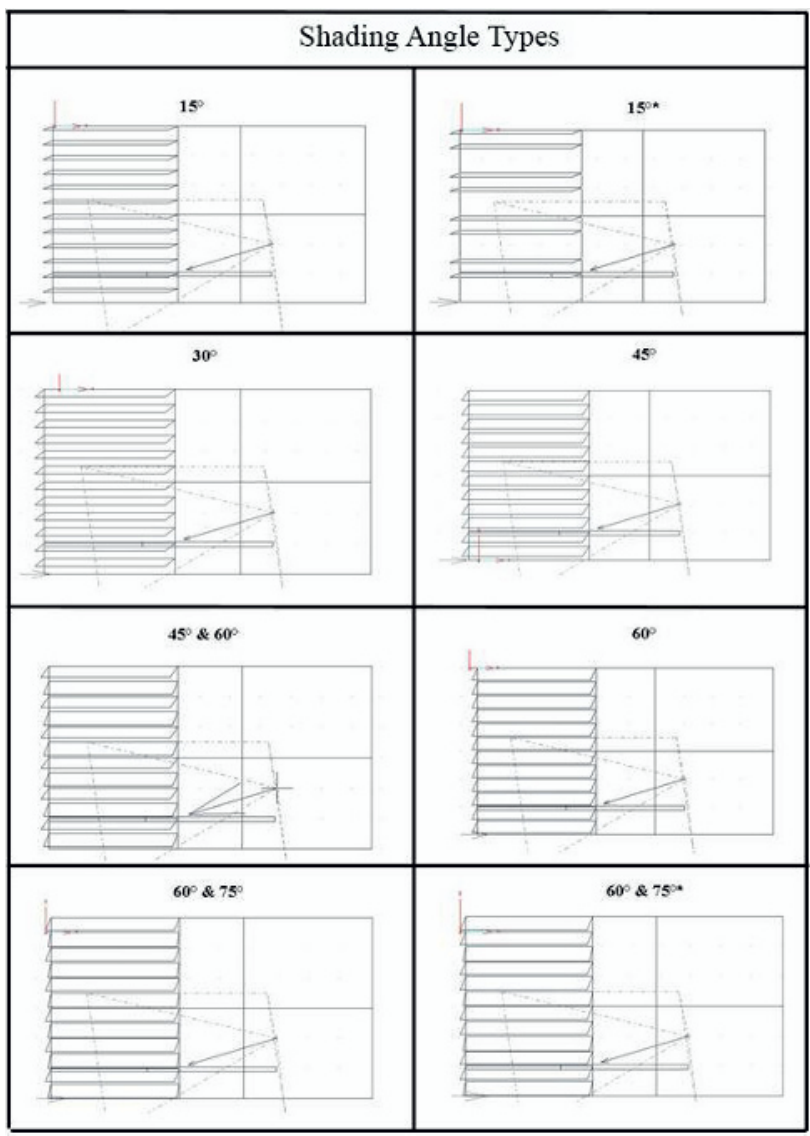

Figure 4. Shading visualization on SOHO units

\section{Parametric camshaft study}

\subsection{Camshaft vs Parametric Camshaft}

This study used camshaft as a mechanism for controlling kinetic movements of adaptive shading system. Camshaft is a shaft to which a cam is fastened or of which forms an integral part, where a cam is a rotating piece in a mechanical linkage used specially in transforming rotary motion into linear motion. The integral parts of a cam are Base circle, Nose, Lobe lift, and Duration (Fig 5.). These parts will be used in this study as the modules in generating parametric camshaft.

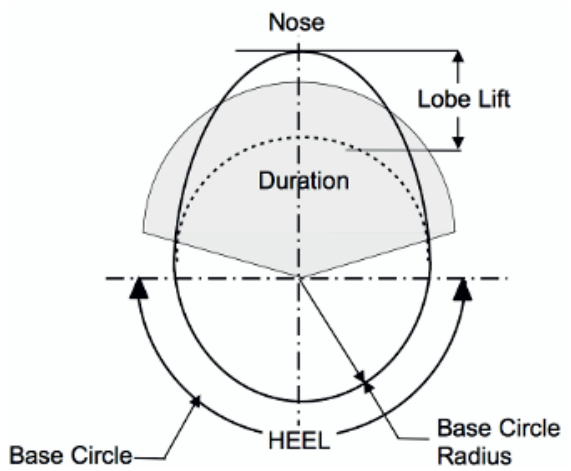

Figure 5. Cam profile used on a car engine. 


\subsection{Parametric Camshaft}

What distinguishes the parametric camshaft in this study is the use of multiple Nose and Lobe lift on each cam. This will result in a non-linear movement and changes. The cam will control the size of the openings of each panel of the shading system.

The main parameters in the parametric camshaft are the length of Lobe lift (L) and the number of Duration $(\mathrm{P})$. Each $\mathrm{L}$ and $\mathrm{P}$ has different values, and the values are determined from the result of shading angle study. Fig. 6 shows the profile of parametric cam and non-linear movements it can generate.

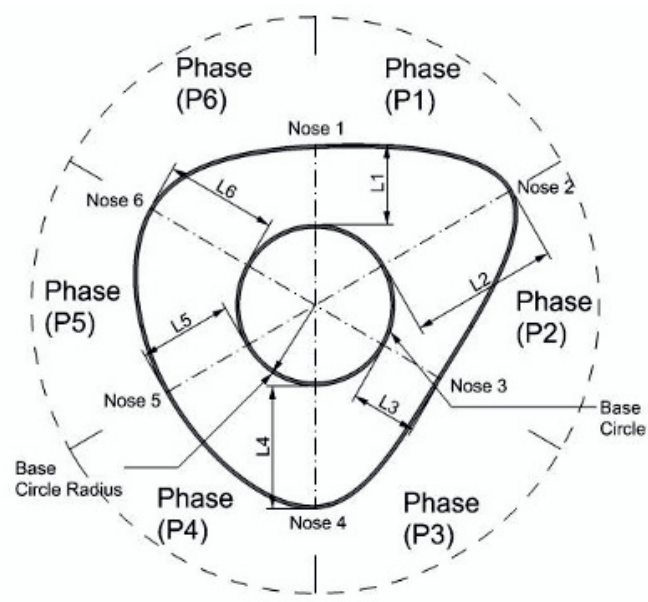

Figure 6. Parametric Cam profile applied in each panel of adaptive shading system.

The result of angle study was used to generate shape of parametric camshaft. The smallest angle was $15^{0}$ and the bigest was $75^{\circ}$, these values were then used as a parameter determining the minimum and maximum length of $\mathrm{L}$ and the number of $\mathrm{P}$. To be able to produce the calculations and parameter settings, this research used algorithmic editor software Grasshopper which is a plugin for CAD software Rhinoceros. Fig. 7 shows the screenshot of the parametric relationship made in Grasshopper.

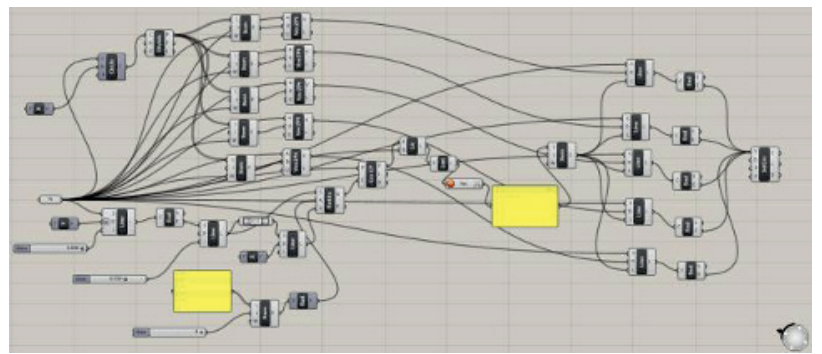

Figure 7. Parametric control and component relationship in Grasshopper.

The algorithm made for controlling the panel was: The smaller shading angle will produce a small value of $\mathrm{L}$ that led to a mechanism to close the panel, while the higher shading angle will produce a large value of $\mathrm{L}$ that led to a mechanism to rotate the panel.
Then, the significant number of changes in daylight level would be used as a determinant of the number of $\mathrm{P}$ in a single cam. In this case a significant changes in the value of radiation on one shading unit was 5 times, therefore the number of $\mathrm{P}=5$ Fig. 8 shows variation of $\mathrm{L}$ and number $P$ in each cam.

Furthermore, the incorporation of cam rotation with specific shapes and driver mechanism would result in angular movements that varied according to the length of $\mathrm{L}$ and the number of $\mathrm{P}$.
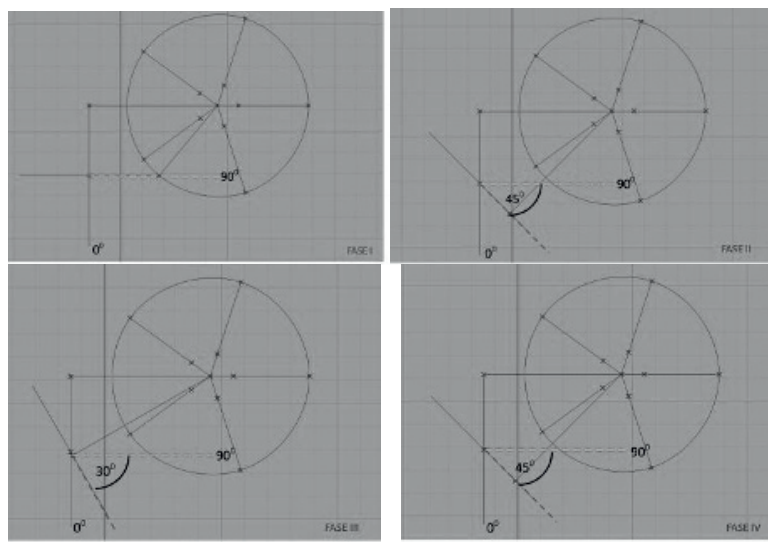

Figure 8. Cam profile study and shading angle result.

Furthermore, a motor would drive the operation of each camshaft. Each camshaft would be driven by a servo motor that rotated according to the number of P. Full turn $\left(360^{\circ}\right)$ would be divided by the number of $\mathrm{P}$ that operated for 12 hours, then off for 12 hours. These settings were done in the microcontroller that collected input data from Grasshopper (Fig. 7) with Firefly plug-in that connects the data from Grasshopper to microcontroller to drive the servo motor. Fig. 9 shows fundamental prototype development of parametric camshaft.

Finally, the whole shading each with own specific camshaft were applied to the facade of the SOHO unit. For one day the surface of this shading system would constantly change to follow the daylight changes. Figure $10,11,12,13$ shows 4 sample types of adaptive shading that could adapt to South and North orientation for the whole day.

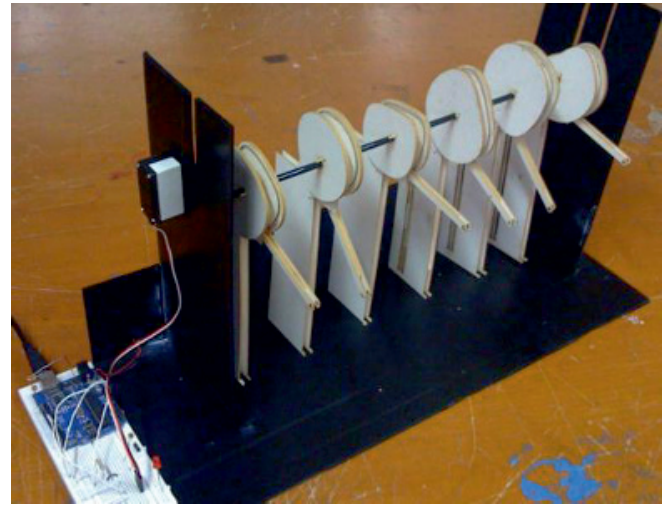

Figure 9. simplified prototype of parametric camshaft. 


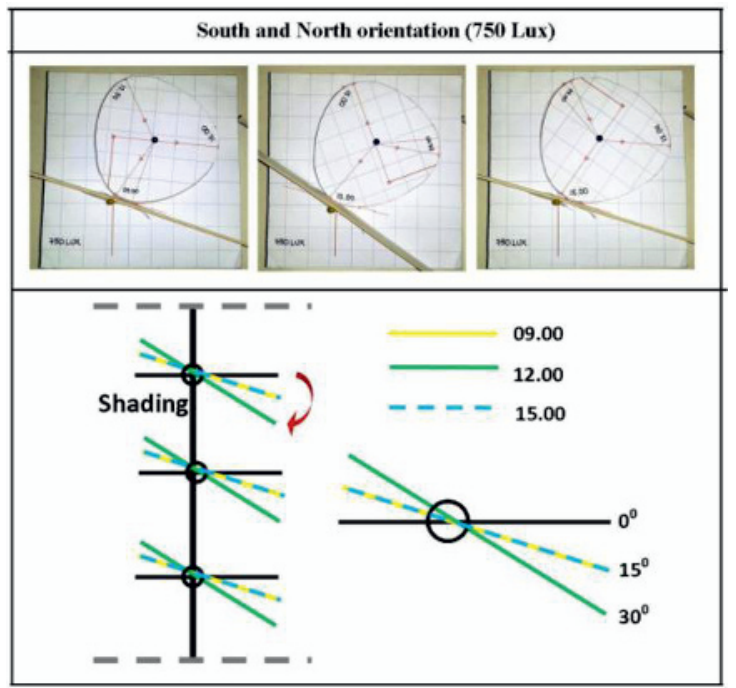

Figure 10. South and North orientation (750 Lux).

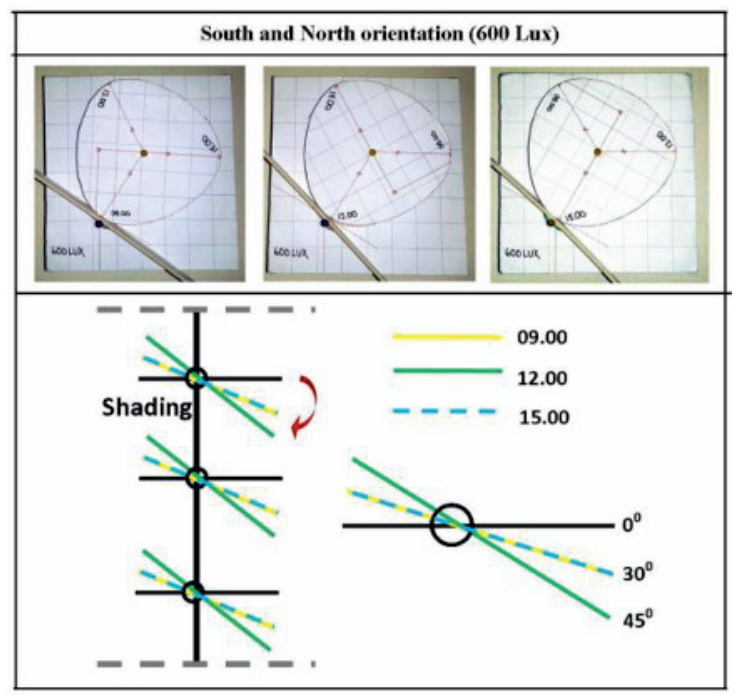

Figure 11. South and North orientation (600 Lux).

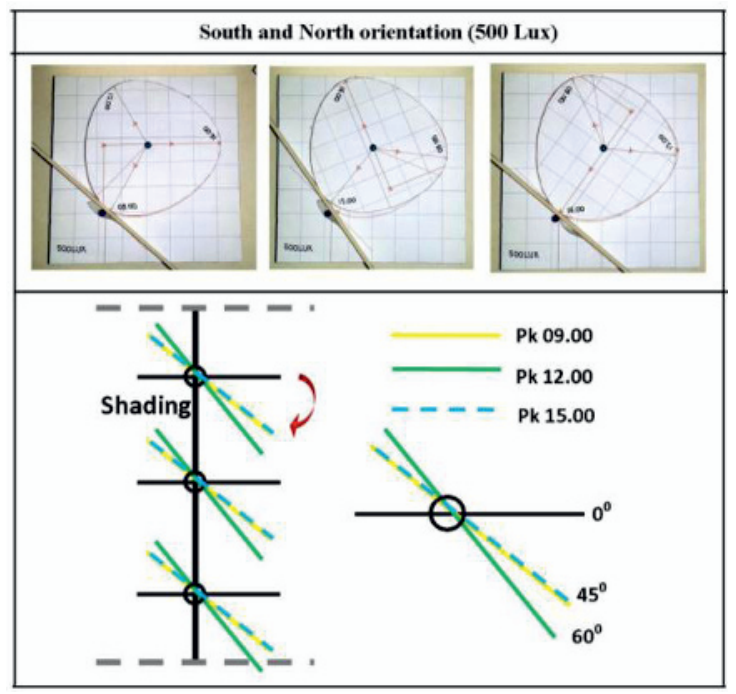

Figure 12. South and North orientation (500 Lux).

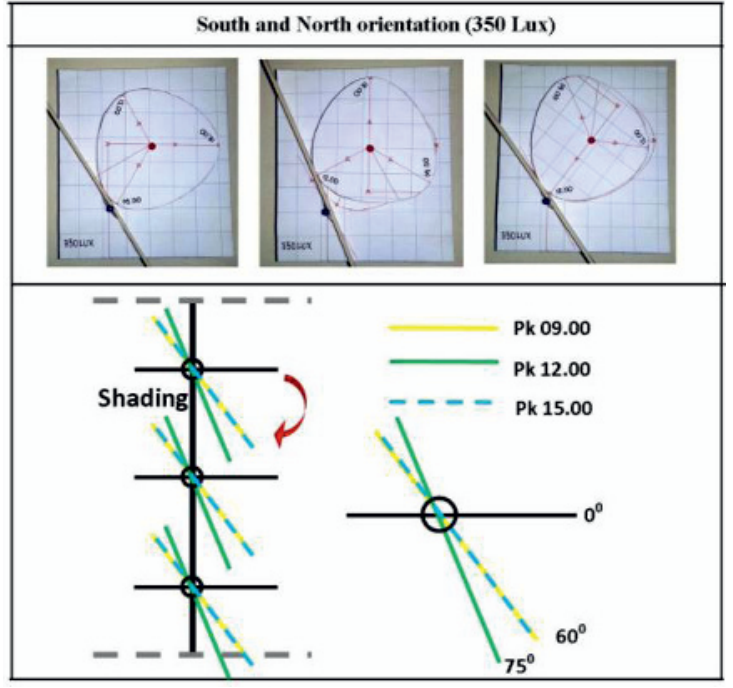

Figure 13. South and North orientation (350 Lux).

\section{Evaluation}

The efficiency of this system could be recognized by comparing to the methods of the widely used system called the Distributed Motorized System (DMS). The DMS uses equipment such as sensors, microcontrollers, motor drivers and motors in large numbers to rotate each fin of the shading device. It works by its sensor that captures the existing environmental conditions as the data to be processed further in the microcontroller to drive the motor through the driver as shown in Fig. 12. Electrical energy that is commonly used in this system is for the operation of the many use of motors and its drivers. On the other hand, Centralized Motorized System (parametric camshaft) uses the analysis data of environmental simulation instead of sensors. The motors used only one on each row so the number of drivers is fewer as well (Fig. 13). Hereby, the electrical energy used to drive the motors could be reduced.

In terms of maintenance on DMS system, if the replacement or service of the motor is required, its large number, position and installation would cause difficulties. Whereas the camshaft parametric system is more in the form of mechanical assemblies which is easier to install and maintain. Motor replacement is easy to perform as well since it requires no wiring to every panel and only one item for each camshaft.

Of all the advantages of this system, the most outstanding is the cost that can be pressed from the time of manufacture, operation until maintenance. 


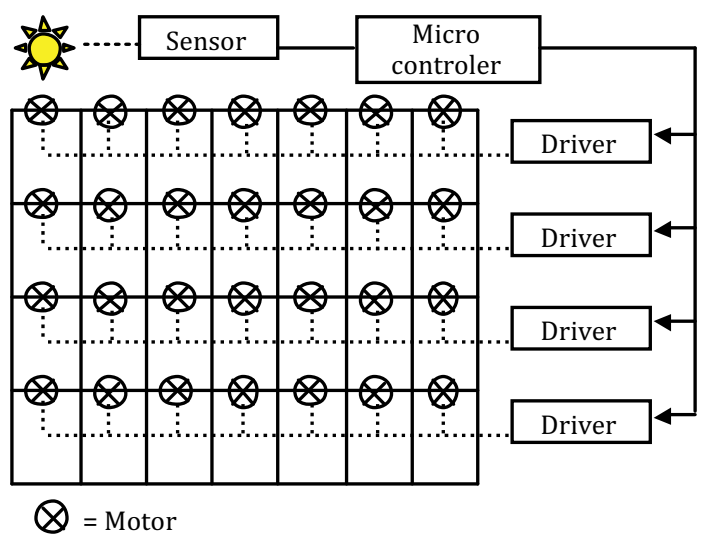

Figure 14. Distributed Motorized System.

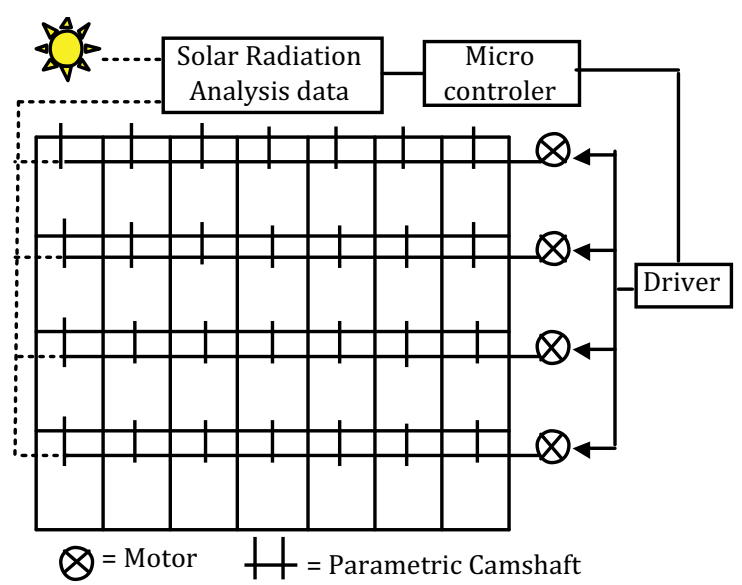

Figure 15. Centralized Motorized System (Parametric Camshaft System)

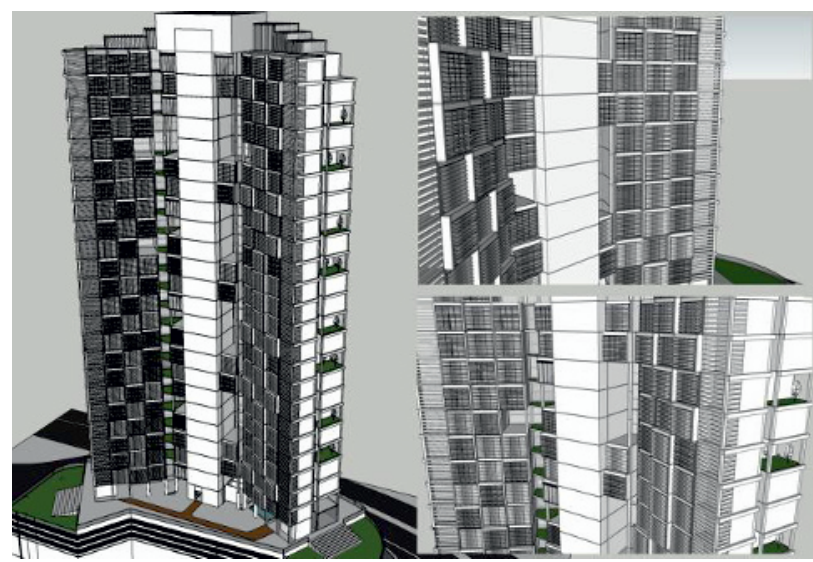

Figure 16. Centralized Motorized System (Parametric Camshaft System)

\section{Conclusion}

This research has shown the effectiveness of using parametric camshaft for controlling kinetic mechanism in adaptive shading system.

The affectivity of this system is observed more enduring in two-seasons climatic conditions whereas not many changes in environmental conditions occurred throughout the year. For example, if the buildings in the tropical countries used adaptive shading system designed for four-seasons climatic conditions, there would be much dissipation, the efficiency and benefits that could be obtained at the four-seasons countries would not be as much compared with the amount of energy required for operation of the system.

In terms of cost-reduction, the application of this system on general buildings (non high profile building) could be applied, so that more users could experience the benefits and advantages of adaptive shading system.

Further research will be focused on the application of materials and assembly. The aim of research is finding the effective materials in terms of durability, cost, methods of easy assembly and maintenance.

Other plans for further research is to build a physical prototype with 1:1 scale. This prototype will be tested on the actual environmental conditions to conduct some adjustments and other findings that could improve the efficiency and effectiveness of this system.

The main targets for these researches are to achieve higher level of sustainability and visual comfort of an adaptive building components.

\section{References}

[1] I. Akmal, SOHO: Small Office Home Office, (2008)

[2] T. Tzempelikos, Integration of Dynamic Facades with other Building Systems, Automated Buildings Magazine, May; 2007.

[3] C.E. Ochoa, I.G. Capeluto, Strategic decision- making for intelligent buildings: Comparative impact of passive design strategies and active features in a hot climate, Building and Environment, vol. 43, p.18291839; 2008 .

[4] R. Hansanuwat, Kinetic Facades as Environmental Control Systems: Using Kinetic Facades to Increase Energy Efficiency and Building Performance in Office Buildings, Master of Building Science Thesis, University of Southern California, May; 2010.

[5] M.E. Skavara, Learning Emergence, Adaptive Cellular Automata Façade Trained by Artificial Neural Networks, Master of Science in Adaptive Architecture \& Computation Thesis, Bartlett UCL, September; 2009.

[6] J. Wang, J. Li, Bio-Inspired Kinetic Envelope for Building Energy Efficiency based on Parametric Design of Building Information Modeling, Power and Energy Engineering Conference, IEEE; 2010.

[7] J. Wang, J. Li, X. Chen, Parametric Design Based on Building Information Modeling for Sustainable Buildings, International Conference on Challenges in Environmental Science and Computer Engineering, IEEE; 2010.

[8] C.C. Sullivan, Robo Buildings. Pursuing the Interactive Envelope, Architectural Record, 0003858X,194: Issue 4; 2006.

[9] F.U. Sjarifudin, Adaptive Building Envelope System using Parametric Camshaft Mechanism for Sustainable Building, Applied Mechanics and Materials Vol.232, pp919-924, 2012 